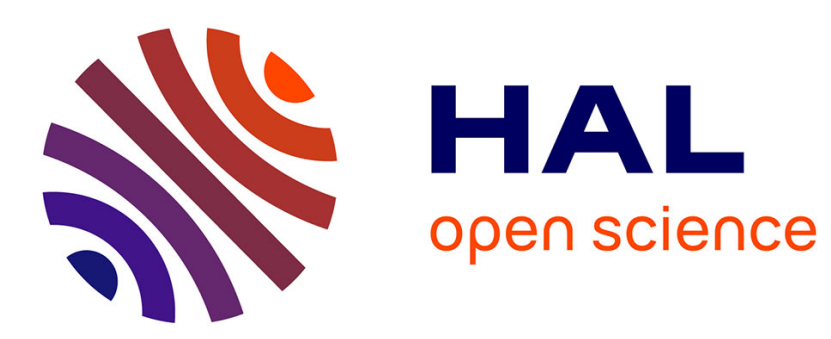

\title{
Integrating process and ontology to support supply chain modelling
}

Tonci Grubic, Ivica Veza, Bozenko Bilic

\section{To cite this version:}

Tonci Grubic, Ivica Veza, Bozenko Bilic. Integrating process and ontology to support supply chain modelling. International Journal of Computer Integrated Manufacturing, 2011, 24 (09), pp.847-863. 10.1080/0951192X.2011.593047 . hal-00724183

\section{HAL Id: hal-00724183 \\ https://hal.science/hal-00724183}

Submitted on 19 Aug 2012

HAL is a multi-disciplinary open access archive for the deposit and dissemination of scientific research documents, whether they are published or not. The documents may come from teaching and research institutions in France or abroad, or from public or private research centers.
L'archive ouverte pluridisciplinaire HAL, est destinée au dépôt et à la diffusion de documents scientifiques de niveau recherche, publiés ou non, émanant des établissements d'enseignement et de recherche français ou étrangers, des laboratoires publics ou privés. 


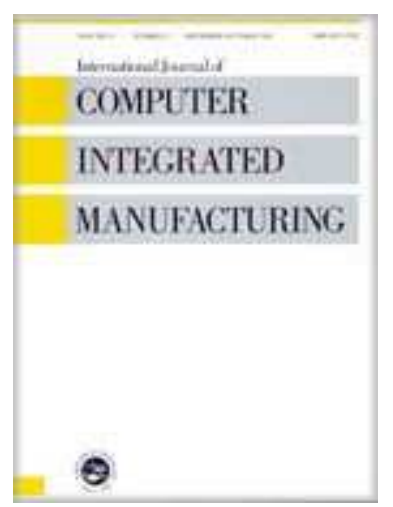

\section{Integrating process and ontology to support supply chain modelling}

\begin{tabular}{|c|c|}
\hline Journal: & International Journal of Computer Integrated Manufacturing \\
\hline Manuscript ID: & TCIM-2011-IJCIM-0053.R1 \\
\hline Manuscript Type: & Original Manuscript \\
\hline $\begin{array}{r}\text { Date Submitted by the } \\
\text { Author: }\end{array}$ & 27-May-2011 \\
\hline Complete List of Authors: & $\begin{array}{l}\text { Grubic, Tonci; Cranfield School of Management, Information } \\
\text { Systems Research Centre } \\
\text { Veza, Ivica; University of Split, Industrial Engineering } \\
\text { Bilic, Bozenko; University of Split, Industrial Engineering }\end{array}$ \\
\hline Keywords: & $\begin{array}{l}\text { ACTIVITY BASED COSTING, PROCESS MODELLING, DECISION } \\
\text { SUPPORT SYSTEMS, SUPPLY CHAIN MANAGEMENT }\end{array}$ \\
\hline Keywords (user): & supply chain, ontology, process, modelling \\
\hline
\end{tabular}

\section{SCHOLARONE" Manuscripts}




\title{
Integrating process and ontology to support supply chain
}

\section{modelling}

\author{
Tonci Grubic, Ivica Veza and Bozenko Bilic \\ Information Systems Research Centre, Cranfield School of Management, Cranfield \\ University, Cranfield, Bedfordshire, MK43 0AL, UK
}

Faculty of electrical engineering, mechanical engineering and naval architecture, University of Split, Croatia 


\begin{abstract}
Many researchers have recognized a lack of common framework to support supply chain modelling and analysis and proposed their solutions accordingly. Majority of the approaches proposed are more concerned with building an object model of a supply chain than identifying processes which realistically describe a supply chain. Though object models provide means or building blocks necessary to model and analyse different elements of a supply chain, an absence of supply chain processes promotes a 'black box' view on the supply chain. This paper proposes an ontology model specifically developed to support supply chain process modelling and analysis. It is founded on a premise that prior identification of processes the ontology is supposed to support facilitates the ontology development and validation. This paper introduces development, validation, and application of supply chain ontology to support supply chain process modeling and analysis.

Keywords: Supply chain; Ontology; Process; Modelling
\end{abstract}

\title{
1. Introduction
}

The interest for supply chain modelling has been steadily growing ever since the topic of supply chain management (SCM) emerged as an area of intensive research some 20 years ago. The approaches proposed are very diverse and range from more general supply chain modelling topics, typified by works of Beamon (1998), Min and Zhou (2002) and Biswas and Narahari (2004), to more specific applications of simulation in supply chain modelling and analysis, as those introduced by Huang et al. (2003), Terzi and Cavalieri (2004), Kleijnen (2005) and van der Zee and van der Vorst (2005).

Many researchers (for example, Biswas and Narahari 2004, Kim and Rogers 2005, Huang et al. 2005, van der Zee and van der Vorst 2005, Jain 2006, Pundoor and Herrmann 2006, Umeda and Zhang 2006) have recognized a lack of common supply chain modelling framework and proposed their solutions accordingly. For example, the framework by van der Zee and van der Vorst (2005) aims to model control structures of 
a supply chain, while framework by Jain (2006) aims to cover different aspects of a supply chain. Unfortunately, they all lack a very important ingredient; a characterisation of relevant supply chain processes. Namely, majority of proposed frameworks are more concerned with building an object model of a supply chain than identifying processes which realistically describe a supply chain. Although object models provide means to represent different elements of a supply chain (for example, activities, resources, inputs, outputs), an absence of relevant processes promotes a 'black box' view on the supply chain. Without a well defined process component no framework can be considered comprehensive enough.

Suppy chain processes capture key activities necessary to plan, source, move, transform, and deliver material, information and services across companies in a supply chain and their internal functional silos. The importance of supply chain processes has long ago been recognized not only among 'main stream' SCM and business process management researchers (for example, Bowersox et al. 2000 and Hammer 2001) but among supply chain modelling research community as well. The latter has usually put a very loose definition on supply chain processes being modelled. Thus, Beamon (1998) identified production/distribution scheduling and inventory management as the most frequently modelled supply chain processes, while in the review by Terzi and Cavalieri (2004) distribution, transportation and inventory planning have been identified as the most implemented supply chain processes. Similar conclusion can also be drawn by analysing the works of Chan and Chan (2005), Hwarng et al. (2005) and Umeda and Zhang (2006). A well defined process model, as it is argued here, provides the context for building relevant object models. The process component not only focuses the work on an object model, but it greatly facilitates its subsequent validation as well. The 
supply chain ontology model introduced here is founded on this premise. This model, developed in a form of generic component library, enables rapid supply chain process modelling. The ontology definition used here builds on Gruber (1993) and Geneserth and Nilsson (1987). Thus, Gruber (1993) defines ontology as a "formal specification of a shared conceptualization", where conceptualization, according to Geneserth and Nilsson (1987), is defined as "the objects, concepts and other entities that are assumed to exist in some area of interest and their inter-relationships." Therefore, on a high level, domain ontology development consists from identifying and designing relevant concepts and their inter-relationships. Framing a domain in a manner which would enable identification of these elements is very important for the successful ontology development project. This role is played by the proposed set of supply chain processes.

The paper is structured as follows. Next section introduces the rationale and elements of the process component which underpin and provide an input for the ontology development presented in the third section. The fourth section presents results from three case studies in the automotive industry conducted to validate the ontology model while section five introduces the application of the ontology model in the context of supply chain process modelling and analysis. Finally, section six concludes the paper by highligting the main achievements and introducing some ideas for future research.

\section{Process component of the supply chain ontology}

The ontology model, introduced in the following section, is part of a wider research project which aimed to develop a business process model of a dyadic or buyer-supplier relationship. This model is viewed as a tool which could help companies in a dyadic relationhip to explore the relationship between their business level and operational level process management. Scope of this model encompasses supply chain processes which 
support material and information flows in a particular buyer-supplier relationship. The relationship between the ontology model and business process model is a direct one. Hence, the ontology model must equip the business process model with a functionality which would support modelling and analysis of different supply chain process configurations that companies in a dyadic relationship may want to explore. Therefore, identification of a right set of material and information flow supported supply chain processes was crucial for further development of the ontology model.

A systematic literature review approach, proposed by Tranfield et al. (2003), was used to identify the relevant supply chain process frameworks. Eigth frameworks have been identified, namely: (1) model by Srivastava et al. (1999), (2) model by Melnyk et al. (2000), (3) model by Mentzer et al. (2001), (4) model by Rudberg et al. (2002), (5) model by Chopra and Meindl (2003), (6) model by Kotzab and Otto (2004), (7) the Global Supply Chain Forum (GSCF) framework, and (8) Supply Chain Operations Reference (SCOR) model. In order to condense the relevant supply chain processes from these frameworks, an evaluation framework had to be devised. For this purpose, the literature review was further extended to encompass the relevant evaluation criteria. The choice of evaluation criteria was guided by the objectives and scope of the generic business process model of a dyadic relationship. The result was an evaluation framework which consists of nine criteria arranged in three groups and described as shown in Table 1.

\section{Table 1 here}

Before the evaluation framework was deployed, some preliminary analysis had been conducted. Thus, it was realised that not all frameworks are relevant for the subsequent evaluation. Namely, the preliminary analysis revealed that apart from the last two 
frameworks, that is, GSCF framework and SCOR model, the other six models do not possess the full potential to be considered for the evaluation. Only the latter two frameworks provide enough details about their supply chain processes necessary for the evaluation.

The SCOR model (Supply Chain Council 2005) has been developed to describe the business activities associated with all phases of satisfying a customer's demand, although it does not attempt to describe every business process or activity. Thus, the model does not address: sales and marketing (demand generation), product development, research and development, and some elements of post-delivery customer support. The model is organized around five primary management processes: (1) plan; (2) source; (3) make; (4) deliver; and (5) return. The GSCF framework, as introduced by Croxton et al. (2001), is developed to describe the standard set of supply chain processes which could be used both between researchers and practitioners. The model consists from eight key processes: customer relationship management process (Croxton et al. 2001), customer service management process (Bolumole et al. 2003), demand management process (Croxton et al. 2002), order fulfilment process (Croxton 2003), manufacturing flow management process (Goldsby and García-Dastague 2003), supplier relationship management process (Croxton et al. 2001), product development and commercialisation process (Rogers et al. 2004), and returns management process (Rogers et al. 2002).

When the frameworks were evaluated (Grubic et al. 2010) the results were diverse (Table 2). Both frameworks were shown to possess some specific advantages and common shortcomings. The common shortcomings were: lack of social consideration 
(C1), almost non existing anatomy of information flow (C5), limited support and representation of 3PL service providers (C7) and no support for allocating costs (C9).

Table 2 here

The overall results suggest the advantage of GSCF framework because this framework addresses more criteria that the SCOR model. Hence, this framework provided a foundation for the further analysis about material and information flow supported supply chain processes. It follows from the description of GSCF processes (Table 3) that customer relationship management and supplier relationship management are used to formulate business level buyer-supplier relationship management. The buyer-supplier business formulations that result from these two processes impact another six supply chain processes, which in this way become operational processes. In a way these two processes are trying to set a bridge between the buyer-supplier business relationship level and the operational level. Starting with a premise that companies in a dyadic relationship have already formulated their business relationship and are now looking for ways to improve it, a generic set of supply chain processes can then be found among the six remaining processes. Since collaborative product development is beyond the scope of the business process model, the following five processes of the GSCF framework were proposed to capture material and information flows in a dyadic relationship: customer service management, demand management, order fulfilment, manufacturing flow management and returns management.

Table 3 here

These processes, it is argued here, frame the material and information flows in a supply chain. Upon their identification, these processes provided a focus and a context for further ontology model development and its subsequent empirical validation. Next 
section introduces the ontology model which captures main building blocks necessary to model the five supply chain processes adopted here.

\section{Supply chain ontology development}

\subsection{Ontology methodology selection}

In recent years ontology has attracted researchers from domains as diverse as supply chain relationships (Ramsay 2005), new product development (Cheung et al. 2006), design requirements management (Sandkuhl and Billig 2007), assembly process modelling (Marsh et al. 2010) to genetics (Gene Ontology 2011). As a result, many ontology development methodologies (for example, Gruber 1995, Grüninger and Fox 1995, Uschold and King 1995, Uschold and Grüninger 1996, Swartout et al. 1997, Fernández-López et al. 1999, Holsapple and Joshi 2002, Mizoguchi 2003, Rajpathak and Chougule 2011) have been proposed. These methodologies differ in various ways, for example: level of formality, the ontology life-cycle addressed, inheritance of a methodology, etc.

Considering the amount of interest, one would expect to easily find an appropriate methodology. Yet, the reality is that the ontology development is still in its infancy and in lack of a robust and agreed method which would ensure successful ontology development. Namely, Guarino and Welty (2002) argue that ontology is still an art rather than engineering discipline, which, according to Gómez-Pérez (2001), is not mature enough to ensure a valid ontology development process and is often being done in an anarchistic manner. Others (Kishore et al. 2004) even claim that the best one can do at a moment is to follow a set of guidelines. Due to all these reasons it was decided 
to adopt a seven step approach proposed by Noy and McGuinness (2002) and depicted in Figure 1.

\section{Take Figure 1 here}

Protégé (Stanford Medical Informatics 2011) frames editor tool, version 3.2, was chosen for building the ontology model. This tool is adopted because it is suited for less experienced and knowledgeable users, it provides fully integrated environment for ontology development and could be installed and used locally. Besides, the software is available for use under an open source-type license as a free download, has software requirements appropriate to the application considered in this investigation and was used in ontology development projects of similar domain (for example, see Lin et al. 2004, Lin and Harding 2007, Ye et al. 2008).

\subsection{Ontology model development}

This section introduces the supply chain ontology development which follows the seven step approach (Figure 1) adopted before and uses Protégé software.

\subsubsection{STEP 1: Domain and scope of ontology}

Noy and McGuinness (2002) suggest that following questions must be answered before the ontology development can commence:

- What is a domain the proposed ontology will cover?

- What the ontology will be used for?

- What questions the ontology will provide answers to?

Domain of ontology model is logistics and SCM while the scope is determined by the five material and information flow supported supply chain processes identified in previous section. The purpose of ontology is to provide key elements, in a form of 
concepts and their relationships, which would support a modelling and analysis of different configurations of the five supply chain processes one may want to explore. In respect to the purpose, questions the ontology will provide answers may include:

- What activities is Demand Management process of company "X" consisted of?

- Which resources are consumed in activities of Returns Management process of company "Y”?

- Which products or services does company "X" offer?

- How long does it take and cost to process a return request for a specific customer?

These questions give an idea about concepts and their relationships which must be captured in order to adequately characterise real-world scenarios pertinent to the five supply chain processes.

\subsubsection{STEP 2: Consider re-using existing ontologies}

Several supply chain ontology models can be found in the literature. Thus, Grubic and Fan (2010) present a review and analysis of existing supply chain ontology models. They have identified six supply chain ontology models: (1) Manufacturing system engineering ontology (Lin et al. 2004, Lin and Harding 2007), (2) Model by Ye et al. (2008), (3) Enterprise Ontology (Uschold et al. 1998), (4) TOVE Ontologies (Fox et al. 1996), (5) Model by Soares et al. (2000), and (6) IDEON ontology (Madni et al. 2001). These models were subsequently analysed by deploying a comparison framework which consists from seven evaluation criteria. The analysis revealed nine gaps (Table 4), where at least two (gaps number one and seven) are particularly relevant here.

Table 4 here 
The first gap relates to granularity captured by the supply chain ontology models. Grubic and Fan (2010) have found that no work has so far been invested into developing a supply chain ontology which would support tactical and operational level decision making. These levels support, for example, planning and transaction of supply chain operations. The second gap deals with a restricted view on a supply chain. Namely, apart from manufacturing activities, no formalisation of other material and information flow supported activities (such as, replenishment, transport, or reverse logistics) was found. These results suggest a lack of ontology which may be considered for re-using. More importantly, they offer an opportunity for the ontology model developed here. Thus, the ontology model proposed here aims to explicitly address these two aspects and in this respect fill the gaps found in existing supply chain ontology models.

\subsubsection{STEP 3: Enumerate important terms in the ontology}

When developing ontology, according to Noy and McGuinness (2002), it is always helpful to make a list of terms pertinent to the domain of study. This list may provide a first step necessary for identifying key concepts and their relationships pertinent for the domain of interest. For the ontology model presented here, the enumeration was conducted by analysing the terms used in SCOR model and GSCF framework respectively. Although the five supply chain processes of the latter were adopted, many of the terms found in the two frameworks are generic to logistics and SCM. What's more, these two frameworks might be the best sources on supply chain processes currently available. 
The enumeration of terms had been conducted separately for SCOR model and GSCF framework. The total number of terms identified in the SCOR model is 361 . Examples of some of the terms found in the SCOR model are shown in Table 5.

\section{Table 5 here}

The total number of terms identified in the GSCF framework is 1453. When enumerating the potentially relevant terms, all eight supply chain processes were included in the analysis. Examples of some of the terms found in the GSCF framework are shown in Table 6.

\section{Table 6 here}

The two lists were then merged together which resulted in 1814 terms. After the duplicates and terms with similar meaning were removed, the result was a list with 1230 potentially relevant terms.

\subsubsection{STEP 4: Define the classes and the class hierarchy}

Obviously, the list of potentially relevant terms was too large, so they were categorised to make the whole process more manageable. As a preliminary step in defining the classes and their hierarchy, the list was reduced to 26 classes. This list is shown in Table 7.

\section{Table 7 here}

The attempt was then made to provide a loose definition for each class. This definition aimed to reflect the scope of the class relative to the domain bounded by the five supply chain processes adopted here. As a consequence this provided a foundation for the second round of the analysis. Thus, when analysed again some of the preliminary classes were outside the scope and were removed from the list. Each class that remained 
was then analysed in order to find any relationship with other classes which resulted in new concepts. An example for this is shown in Table 8.

\section{Table 8 here}

Once when all the preliminary classes and their inter-relationships had been mapped, the work on defining classes and their hierarchy started. The result was a list of 62 classes, fraction of which is presented in Figure 2.

\section{Take Figure 2 here}

At the highest level, these classes have been arranged into two abstract classes: General_View and Supply_Chain_View; which serve mainly as umbrella classes to encompass subclasses with similar characteristics. The former further contains the following classes: Annotation, Asset, Coordination, Location, Metric, Process/Activity, QuantityRelationships, and Resource; and the latter contains: Buyer, Flow, Person, Supplier, and System. Each of these serves as a super-class subsuming further classes. Some of these classes are also shown in Figure 2. Due to space limitations a complete overview of all classes and their properties is not provided here although this information will be provided by the corresponding author upon request.

\subsubsection{STEP 5: Define the properties of classes - slots}

Class properties, in Protégé also known as slots or attributes (Sharman et al. 2004), were created for the classes defined in previous step. These properties aim to capture some semantic information pertinent to the class. Wand et al. (1999) argue that a class has two types of properties: (1) intrinsic, and (2) mutual or relational. An intrinsic property depends on a class, while mutual or relational property may also depend on other classes. The former type of properties is usually used to, for example, indicate a name of a class, and the latter type denotes a relationship with another class. For 
example, in the ontology model an Organisation is modelled in a manner so it can at the same time be a Buyer and Supplier, which buys some PartGroup and/or ServiceGroup from its suppliers in order to transform these into ProductGroup and/or ServiceGroup for its buyers. This example outlines a relationship that exists between an instance of Organisation class which could have many instances of the PartGroup, ServiceGroup and ProductGroup classes. Therefore, the class Organisation has a property named buys_Part/Service that is of type ServiceGroup and/or PartGroup, which aims to depict different parts and/or services the company might be buying.

Unfortunately, no 'recipe' which would facilitate definition of the properties of a class exists. In defining the properties of classes, in addition to the advice made by (Wand et al. 1999) and the results of the analysis from the previous step, domain knowledge and experience were used.

\subsubsection{STEP 6: Define the facets of the slots}

After properties or slots had been defined, facets definition followed. A facet is used to characterise different features a value of the slot can take. These features might correspond to a value type (Integer, Float, String, or Instance) or allowed number of items which may be associated with a slot. For example, the relational slot buys_Part/Service has two facets. The first relates to the type of values the slot can take. This corresponds to instances of classes ServiceGroup and/or PartGroup classes. The second facet depicts a number of items this slot can take, which in this case is multiple since an instance of Organisation might be buying multiple instances of ServiceGroup and/or PartGroup classes at a same time. 


\subsubsection{STEP 7: Create instances}

Built in this way the ontology model offers a library of building blocks necessary to characterise the five material and information flow supported supply chain processes of the GSCF framework. Besides, it can also serve as a knowledge representation and acquisition tool. This is particularly relevant for the validation phase since it allows direct input of data. The ontology model was validated in two steps. The first step involved the project team members and an example depicting a real supply chain situation. The second step, introduced next, aimed to validate and further enrich the ontology model with three case studies of material and information flows.

\section{Case studies to validate the ontology model}

In order to investigate the validity of process and ontology components of material and information flow supported supply chain processes adopted here, a case study research was conducted. While the results on the validity of five supply chain processes were reported elsewhere (Grubic et al. 2008), the results on ontology component are reported here. Case study research was adopted since it enables an observation of actual practices (Meredith 1998), has a greater understanding of the nature and complexity of research phenomenon (Ellram 1996, Meredith 1998, Yin 2003) and provides much needed exploratory depth (Meredith 1998).

\subsection{Case study design}

When designing a case study the following five elements have to be properly considered and addressed (Yin 2003): (1) case study questions, (2) case study propositions (if any), (3) units of analysis, (4) logic linking the data to the propositions, 
and (5) criteria for interpreting the findings. In respect to this research, these elements are defined in Table 9.

Table 9 here

A key issue when designing a case study research is whether to adopt a single or multiple case study design. For this research a multiple-case study design was adopted. Three case studies, each encompassing two companies: a buyer and supplier, which cover almost the entire automotive supply chain, from a raw material supplier to aftermarket, were selected. These companies provide a richness of contexts, which is expressed by their: supply chain position, size, volume, yearly turnover, product range, organisational complexity, etc; which further contribute to overall generalisability of findings. Besides, due to competition, globalisation, legacy and some other characteristics, companies in the automotive industry can be considered as representative or typical cases to study. The first case study was in automotive manufacturing, where second and third case studies were in automotive aftermarket sector. Figure 3 shows how each of the six case study companies are positioned relative to the overall supply chain.

Take Figure 3 here

\subsection{Case study execution}

The scope of a case study reflects the flows of material and information for a specific product or a family of products from the order fulfilment cycle at the buyer's side to replenishment cycle at the supplier's side. For the execution of case studies a data collection protocol was developed. It consists from three lists of questions that correspond to three levels of detail, company level, specific process level and activity level, and were used separately for each company. The aim of company level interview 
was to build a high level knowledge about supply chain processes and their interdependencies, process owners, departments these processes cut across and supporting IT systems for a specific flow of materials in a dyadic relationship as bounded by the scope above. Building on these findings, process level interviews were then conducted with process owners from different functions and seniority levels (for example, head of supply chain, head of customer service, warehousing manager, buyer in purchasing, manufacturing manager, manufacturing planner and logistics coordinator, etc.). The aim was to build a clear picture of a specific supply chain process. Activity level interviews were conducted in case more detail about specific process activity was required. In total, more than 50 interviews were conducted which were triangulated with secondary data (for example, process and organisational charts), and direct observations. A high-level overview of all the case studies and studied companies is provided in Table 10.

\section{Table 10 here}

\subsection{Case study analysis and synthesis}

With a supply chain process as a major unit of analysis, the analysis of empirical studies has been structured on three levels: (1) company level; (2) case study level; and (3) cross-case study level. For every company in each of the three case studies, upon collecting the necessary data, relevant supply chain process maps had been developed and subsequently validated with each company. For example, in case of Company A two supply chain processes were identified which structure material and information flows with the Company B. Maps for these processes were developed based on the interviews collected and supported with the secondary data. Following this, the maps were validated with relevant individuals from the company which then provided input to 
the ontology model validation. By instantiating classes of the ontology model which capture relevant concepts of the identified supply chain processes, ontology was then produced for every company of all three case studies. This was done by using the knowledge acquisition functionality enabled by the classes and class properties of the ontology model. As an example, Figure 4 shows only a fraction of data captured in the ontology model of the first case study.

\section{Take Figure 4 here}

During the execution of case studies, a great deal of data were collected (e.g. product designs, BOMs, organisational charts, information system maps, etc.) but only those data that are directly relevant for representing and modelling the five supply chain processes were used to validate the ontology model. Consequently, some ontology classes have not been instantiated. It may be that these classes are not relevant for the type of model being developed here, although they may provide utility for other types of analysis. Hence, before the capabilities of the ontology model can be assessed in their entirety, these will have to be empirically validated by some future empirical studies. As a result a heuristic can be proposed according to which ontology can be developed as being either: (1) exhaustive representation of a domain or (2) too generic. The former would mean developing an ontology which encompasses many domain dependent classes with varying levels of relevance. This is the case with the ontology model developed here. Other way would be to define only a small number of classes that are generic to a domain and leave the users to develop other classes which may be more relevant for their application. Either approach has advantages and disadvantages which must be weighted relative to the objectives of the ontology model. 
Once when the ontology models of all three case studies had been populated, crosscase study analysis was conducted. Ontology validation is a complex and rather under researched topic which makes synthesis of cross-case study ontology investigation even more challenging. Namely, Grubic and Fan (2010) have pointed on the complete absence of empirical or field based research in supply chain ontology research which qualifies this research as a pioneering work in this area. Nevertheless, as a result of cross-case study analysis of the ontology model the following four findings were made.

\subsubsection{Supply chain processes are multidimensional}

There is an emerging pattern occurring in all case studies which suggests a considerable diversity in their supply chain processes. In order to develop more realistic and better supply chain process models, these have to be captured and represented appropriately. The ontology model is founded on a premise of the existence of some generic set of supply chain processes. These reflect the five adopted processes of the GSCF framework and are captured in the GenericProcess and GenericActivity classes. Hence, the GenericProcess class models a specific supply chain process of a company, for example, CSM process, in a generic way irrespective of any particular customer. Similarly, GenericActivity class is used to model activities of a GenericProcess instance. Particular CSM process, for a particular customer, is modelled relative to its generic counterpart. What this means is that a company may have a portfolio of CSM processes designed and managed to meet the needs of specific customers. Further to this, even if executed for a specific customer, a supply chain process may diverge further. For example, inside a specific CSM process, being executed for a specific customer, a variety of flows may exist which differ relative to, for example, type of 
order, type of request, or order route. Example for this, based on one of the case study companies, is presented in Table 11.

Table 11 here

In the case of CSM process, there are three dimensions which govern and drive diversity in this process. These are: customer type, customer request type, and product type. In respect to customer type, CSM process needs to serve three kinds of customers, that is: branch, retail, and trade customers. Among themselves, these customers place four types of requests: inter-branch order request, return request, special order request, and stock order request. Finally, any of the three types of customers can place any of the four request types for any of the 20,000 stock keeping units (SKUs) of Company C. Taken together, these dimensions account for seven different combinations which govern the operation of CSM process and which need to be considered when modelling and analysing its performance.

Each of these three dimensions brings additional layer of complexity to the ontology model. Consequently, ontology model has been changed to accommodate the effects of supply chain process multidimensionality. Namely, each dimension of each process requires a capability to model a set of conditions that is unique for specific combination of dimensions in a certain supply chain process. For example, in order to calculate the total cost for fulfilling a certain type of order, for a certain type of customer of the OF process in Table 11, it may be necessary to define activities, resources (human and equipment), information systems, inputs, outputs, etc; relative to this combination of dimensions. On top of this, each of these combinations can further differ for specific product or service provided. Therefore, to realistically support supply chain process modelling appropriate changes to the ontology model have been made. 


\subsubsection{Not all supply chain processes are equally relevant}

Analysis of the case study data for the process component (Grubic et al. 2008) revealed that not all supply chain processes may be equally important for a company. Namely, not a single company was found which executes all five supply chain processes (see Table 10). This finding might be explained with a limited number of case studies or in a decision to focus on just a subset of a total flow of materials between a company and its supplier/customer. Although this finding calls for more exploratory research, nevertheless, it has a clear implication on the content of the ontology model.

\subsubsection{Boundaries of supply chain processes are vague}

Similar to the previous finding, and because of its relevance for this study, this finding has also been included from the analysis of the case study data of the process component. Because of their significant interdependency, a clear boundary between supply chain processes was sometimes hard to set. For example, CSM process of company $\mathrm{C}$ in one of its activities interfaces with the OF process. This activity involves a customer service representative initially communicating with a customer to identify nature of its request and subsequently placing an order and booking it through a computer system. Even when we discussed this issue with the company involved they were not clear whether this activity falls within the realm of CSM or OF process. But assuming the five supply chain processes adopted here adequately capture the entirety of material and information flows, the following can be proposed. These processes may be perceived as a system consisted of five different and interdependent subsystems. This then suggests that a further research into adequate system/subsystem decomposition is required. Ontology can again be of help here. Thus, Wand and Weber (Wand and Weber 1990, Wand and Weber 1995) proposed how ontology theory can be used in 
finding an optimal decomposition of an information system. By employing the proposed approach a similar analysis could be done with an aim to find an optimal decomposition of five supply chain processes.

\subsubsection{Process perspective facilitates supply chain ontology development and} validation

Compared with the existing ontology modelling and supply chain ontology literature, the ontology model introduced here is based on a premise that prior identification of processes the ontology is supposed to support not only facilitates its development but subsequent validation also. Therefore, preceding the ontology development, five supply chain processes which support the material and information flows had been identified. These were then used as a foundation for ontology development. Once developed, the ontology was then validated with in-depth case studies in three dyadic relationships. Although some changes had to be made, mainly in respect to multidimensional nature of supply chain processes, no major structural or conceptual work was necessary to accommodate those changes. To some extent this provides a 'proof of concept' for the proposed ontology development approach. Namely, as it is argued here, having identified a process component will greatly facilitate development of ontology and its subsequent validation and, what is more, it will even enhance the capability and supportability of ontology.

\section{Application of developed supply chain ontology}

This section presents an application of supply chain ontology developed and validated as introduced above. Following the validation, four supply chain process models for companies from two case studies were developed by applying the ontology 
model. These models correspond to companies from case studies two and three (Table 10). Models for companies of the case study one could not be developed due to some trust and costing issues. Namely, the supplier was very reluctant to share process and costing data fearing this might be used by the customer to further drive their profit down. Nevertheless, all four supply chain process models were developed by applying the ontology model proposed here and later given to these companies for their use. The application of ontology model is demonstrated on the case of supply chain process model of Company C. This example shows how classes of the ontology model, and the five supply chain processes of the GSCF framework, can be used to support the modelling and analysis of time and cost in supply chain processes. Due to confidentiality reasons, real time and cost data have been replaced by dummy figures.

The first step in applying the ontology model was translation of its classes and their properties into an environment which would enable their use for the supply chain process modelling and analysis. This was done manually in Enterprise Modeller (EM) software tool. EM not only provides an environment necessary for modelling and analysis of business processes, but more importantly it enables creation of customised model frameworks which support specific business process modelling and analysis needs. This functionality was particularly interesting since it enabled translation of ontology model classes and their properties. The result was a list of objects which form generic component library that supports supply chain process modelling and analysis. This is shown in Figure 5.

\section{Take Figure 5 here}

Next step was to characterise processes identified through empirical phase of research. In case of Company $\mathrm{C}$ this involved modelling of four supply chain processes 
(Figure 5), namely: (1) Customer service management, (2) Demand management, (3) Order fulfilment, and (4) Returns management process. The characterisation involved mapping the activities and capturing the key information necessary for their description and analysis. Each activity of each of the four supply chain processes was described in terms of, for example: material and information inputs and outputs, human and physical resources consumed and various time elements (for example, set-up time, value-added time, non value-added time). This information was crucial for the calculation and analysis of total time and cost consumed by the supply chain process.

Representing key information which characterise an activity was made possible by changes on the ontology model that resulted after realising the supply chain process multidimensionality nature. This emerged from case studies and demanded a change in the ontology model which would provide a capability first to capture and second to model a set of conditions that is unique for the operation of a supply chain process. In case of the CSM process of Company C this includes three dimensions (Table 11) which have to be taken into consideration in order to make better and more realistic supply chain process analysis. Hence, the CSM process was modelled in a way that captures the most important combinations relevant for its operation. This is shown in Figure 6.

\section{Take Figure 6 here}

As the figure above shows the operation of CSM process is characterised by seven combinations presented as seven different colours. For example, combination presented by red colour describes operation of this process in case of branch customers who are placing special order requests for clutch group of products. This means that an activity of CSM process may concurrently be involved in various combinations relevant for the 
operation of this process. This requires a functionality to separate modelling and analysis of these combinations not only on the whole process but on the activity level also. The latter is shown on Figure 7.

\section{Take Figure 7 here}

This figure shows activity 'Find an alternative supplier' of the CSM process of Company C. It also shows that this activity is at the same time involved in two different combinations which are relevant for its operation. One is for branch and the other is for trade customers in case where both place special order request for a clutch. This figure also shows the equipment costs incurred in the operation of the two combinations. Information about other elements (for example, building or human resource cost) necessary to calculate the cost and time consumed by other combinations involved in the operation of this activity can be provided in a similar manner. By providing all this information for all activities a total time and cost of a supply chain process can be calculated. This information is very important for the management and analysis of supply chain processes especially in cases where improvement in terms of efficiency and effectiveness is sought. By means of the ontology model introduced here this analysis is further augmented because it supports modelling and analysis of supply chain processes in respect to other factors (specific customer, product type or group, marketing channel, distribution channel) and their inter-relationships. This kind of analysis is of utmost importance for studies which involve the improvement of operations by introducing new procedures or technologies.

\section{Conclusions and future work}

This paper has introduced development, validation, and application of ontology model to support supply chain process modelling and analysis. The impetus for this 
came upon realising that the majority of existing supply chain modelling approaches fail to identify and characterise a valid set of supply chain processes, thus taking a rather 'black box' view on a supply chain. Namely, a great deal of supply chain modelling approaches have been developed to solve and support a variety of supply chain related problems but most of them fall short to identify and articulate the key business processes. Neglecting this aspect of supply chains would be erroneous since supply chain business processes, by means of materials, information, and services, connect business partners in a supply chain. Hence, the ontology proposed here is premised on an idea that prior identification of processes the ontology is supposed to support greatly facilitates its development and subsequent validation. As a precursor to ontology model development, a review and analysis of supply chain process frameworks was conducted to identify a set of material and information flow supported supply chain processes which realistically describe a supply chain. These flows are recognised as the core of logistics and supply chain management discipline and have been adopted as a key unit of analysis. This resulted with the identification of five supply chain processes (customer service management, demand management, order fulfilment, manufacturing flow management, and returns management process) of the Global Supply Chain Forum framework. The identified processes then provided a context, focus, and foundation for further development of the ontology model. Upon its development, the ontology model was validated through in-depth case studies of three dyadic relationships which encompass almost the entire automotive supply chain. The ontology model was then used to build four supply chain process models of real industrial supply chain settings and subsequently given to companies involved for their use. 
The main achievements of this research can be summarised as: (1) identification and characterisation of a set of supply chain processes which realistically describe material and information flows and which provided input for the ontology development; (2) development of an ontology model which captures key concepts and their relationships of this set in an implementation neutral way; (3) addressing some of the gaps, mainly by developing the ontology model which explicitly supports tactical and operational level decision making across all the major material and information flow activities, in existing supply chain ontology models; (4) an extensive empirical investigation into real supply chain processes which enabled validation and further enrichment of the ontology; and (5) an initial application of the ontology. Nevertheless, a further research is necessary especially in the area of testing the ontology's applicability. More specifically, this would involve testing the ontology in other contexts, with other companies in automotive sector but also testing it in other industry sectors, for example, electronics, aerospace, consumer goods, food, etc. Further opportunity also arises for enriching the ontology with some empirical studies of supply chain processes in manufacturing companies. Namely, this research investigated only two companies of such kind, hence the need for more research in this area is called for. The authors are currently trying to engage with industrial partners to address some of these opportunities. Finally, exposing the ontology model to real industrial settings led to several findings. Although a considerable effort had been invested in designing and executing the empirical research, mainly due to limited number of case studies conducted, these findings should be understood as propositions or hypotheses which demand further investigation. 


\section{References}

Beamon, B. M., 1998. Supply chain design and analysis: models and methods. International Journal of Production Economics, 55 (3), 281-294.

Biswas, S. and Narahari, Y., 2004. Object oriented modelling and decision support for supply chains. European Journal of Operational Research, 153 (3), 704-726.

Bolumole, Y. A., Knemeyer, A. M. and Lambert, D. M., 2003. The customer service management process. The International Journal of Logistics Management, 14 (2), 15-31.

Bowersox, D. J., Closs, D. J. and Stank, T. P., 2000. Ten mega-trends that will revolutionize supply chain logistics. Journal of Business Logistics, 21 (2), 1-16.

Chan, F. T. S. and Chan, H. K., 2005. The future trend on system-wide modelling in supply chain studies. International Journal of Advanced Manufacturing Technology, 25 (7-8), 820-832.

Cheung, W. M., Bramall, D. G., Maropoulos, P. G., Gao, J. X. and Aziz, H., 2006. Organizational knowledge encapsulation and re-use in collaborative product development. International Journal of Computer Integrated Manufacturing, 19 (7), 736-750.

Chopra, S. and Meindl, P., 2003. What will drive the enterprise software shakeout? Supply Chain Management Review, 7 (1), 50-56.

Croxton, K. L., 2003. The order fulfilment process. The International Journal of Logistics Management, $14(1), 19-32$.

Croxton, K. L., García-Dastague, S. J., Lambert, D. M. and Rogers, D. S., 2001. The supply chain management processes. The International Journal of Logistics Management, 12 (2), 13-36.

Croxton, K. L., Lambert, D. M., García-Dastague, S. J. and Rogers, D. S., 2002. The demand management process. The International Journal of Logistics Management, 13 (2), 51-66.

Ellram, L., 1996, The use of the case study method in the logistics research. Journal of Business Logistics, 17 (2), 93-138. 
Fernández-López, M., Gómez-Pérez, A., Sierra, J. P. and Sierra, A. P., 1999. Building a chemical ontology using Methontology and the ontology design environment. IEEE Intelligent Systems, 14 (1), 37 46.

Fox, M. S., Barbuceanu, M. and Grüninger, M., 1996. An organization ontology for enterprise modelling: preliminary concepts for linking structure and behaviour. Computers in Industry, 29 (1-2), 123-134.

Gene Ontology [online], Available from: www.geneontology.org, [Accessed February 2011].

Genesereth, M. R. and Nilsson, N. J., 1987. Logical Foundation of Artificial Intelligence, Los Altos, California: Morgan Kauffman.

Goldsby, T. J. and García-Dastague, S. J., 2003. The manufacturing flow management process. The International Journal of Logistics Management, 14 (2), 33-52.

Gómez-Pérez, A., 2001. Evaluation of ontologies. International Journal of Intelligent Systems, 16 (3), 391-409.

Gruber, T. R., 1993. A Translation Approach to Portable Ontology Specification. Knowledge Acquisition, $5(2), 199-220$.

Gruber, T. R., 1995. Towards Principles for the Design of Ontologies Used for Knowledge Sharing. International Journal of Human-Computer Studies, 43 (5-6), 907-928.

Grubic, T. and Fan, I.-S., 2010. Supply chain ontology: review, analysis and synthesis. Computers in Industry, 61 (8), 776-786.

Grubic, T., Bastl, M., Fan, I.-S., Harrison, A. and Templar, S., 2010. Towards the integrative supply chain model. International Journal of Logistics: Research and Applications, 13 (1), 59-73.

Grubic, T., Bastl, M., Fan, I.-S., Templar, S. and Harrison, A., 2008. An empirical study of supply chain processes in the automotive industry, 15th International Annual Euroma conference, 15-18 June, Groningen, The Netherlands.

Grüninger, M. and Fox, M. S., 1996. Methodology for the design and evaluation of ontologies. In the Proceedings of the IJCAI'95, Workshop on Basic Ontological Issues in Knowledge Sharing, Montreal, Canada. 
Guarino, N. and Welty, C., 2002. Evaluating ontological decisions with ontoclean. Communications of the ACM, 45 (2), 61-65.

Hammer, M., 2001. The superefficient company. Harvard Business Review, 79 (8), 82-91.

Holsapple, C. W. and Joshi, K. D., 2002. A collaborative approach to ontology design. Communications of the ACM, 45 (2), 42-47.

Huang, G. Q., Lau, J. S. K. and Mak, K. L., 2003. The impacts of sharing production information on supply chain dynamics: a review of the literature. International Journal of Production Research, 41 (7), $1483-1517$.

Huang, S. H., Sheoran S. K. and Keskar, H., 2005. Computer-assisted supply chain configuration based on supply chain operations reference (SCOR) model. Computers \& Industrial Engineering, 48 (2), 377 394.

Hwarng, H. B., Chong, C. S. P., Xie, N. And Burgess, T. F., 2005. Modelling a complex supply chain: understanding the effect of simplified assumptions. International Journal of Production Research, 43 (13), 2829-2872.

Jain, S., 2006. A conceptual framework for supply chain modelling and simulation. International Journal of Simulation and Process Modelling, 2 (3/4), 164-174.

Kim, J. and Rogers, K. J., 2005. An object-oriented approach for building a flexible supply chain model. International Journal of Physical Distribution \& Logistics Management, 35 (7), 481-502.

Kishore, R., Sharman, R. and Ramesh, R., 2004. Computational Ontologies and Information Systems: I. Foundations. Communications of the Association for Information Systems, 14, 158-183.

Kleijnen, J. P. C., 2005. Supply chain simulation tools and techniques: a survey. International Journal of Simulation and Process Modelling, 1 (1/2), 82-89.

Kotzab, H. and Otto, A., 2004. General process-oriented management principles to manage supply chains: theoretical identification and discussion. Business Process Management Journal, 10 (3), 336-349.

Lin, H. K. and Harding, J. A., 2007. A manufacturing system engineering ontology model on the semantic web for inter-enterprise collaboration. Computers in Industry, 58 (5), 428-437. 
Lin, H. K., Harding, J. A. and Shahbaz, M., 2004. Manufacturing system engineering ontology for semantic interoperability across extended project teams. International Journal of Production Research, $42(24), 5099-5118$.

Madni, A. M., Lin, W. and Madni, C. C., 2001. IDEONTM: an extensible ontology for designing, integrating and managing collaborative distributed enterprises. Systems Engineering, 4 (1), 35-48.

Marsh, R., Jonik, M., Lanham, J., Cheung, W. M., Newnes, L. B. and Mileham, A. R., 2010. Modelling an assembly process using a close coupled generative cost model and a discrete event simulation. International Journal of Computer Integrated Manufacturing, 23 (3), 257-269.

Melnyk, S. A., Stank, T. P. and Closs, D. J., 2000. Supply chain management at Michigan State University: the journey and the lessons learned. Production and Inventory Management Journal, 41 (3), $13-18$.

Mentzer, J. T., DeWitt, W., Keebler, J. S., Min, S., Nix, N. W., Smith, C. D. and Zacharia, Z. G., 2001. Defining supply chain management. Journal of Business Logistics, 22 (2), 1-25.

Meredith, J., 1998. Building operations management theory through case and field research. Journal of Operations Management, 16 (4), 441-454.

Min, H. and Zhou, G., 2002. Supply chain modelling: past, present and future. Computers \& Industrial Engineering, 43 (1-2), 231-249.

Mizoguchi, R., 2003. Tutorial on ontological engineering: ontology development, tools and languages (Part 2). New Generation Computing, 22 (1), 61-96.

Noy, N. F. and McGuinness, D. L., 2002. Ontology Development 101: A Guide to Creating Your First Ontology. Stanford University, Stanford, CA, Stanford Medical Informatics Report SMI-2001-0880.

Pundoor, G. and Herrmann, J. W., 2006. A hierarchical approach to supply chain simulation modelling using the Supply Chain Operations Reference model. International Journal of Simulation and Process Modelling, 2 (3/4), 124-132.

Rajpathak, D. and Chougule, R., 2011. A generic ontology development framework for data integration and decision support in a distributed environment. International Journal of Computer Integrated Manufacturing, 24 (2), 154-170. 
Ramsay, J., 2005. The real meaning of value in trading relationships. International Journal of Operations \& Production Management, 25 (6), 549-565.

Rogers, D. S., Lambert, D. M. and Knemeyer, A. M., 2004. The product development and commercialization process. The International Journal of Logistics Management, 15 (1), 43-56.

Rogers, D. S., Lambert, D. M., Croxton, K. L. and García-Dastague, S. J., 2002. The returns management process. The International Journal of Logistics Management, 13 (2), 1-18.

Rudberg, M., Klingenberg, N. and Kronhamn, K., 2002. Collaborative supply chain planning using electronic marketplaces. Integrated Manufacturing Systems, 13 (8), 596-610.

Sandkuhl, K. and Billig, A., 2007. Ontology-based artefact management in automotive electronics. International Journal of Computer Integrated Manufacturing, 20 (7), 627-638.

Sharman, R., Kishore, R., Ramesh, R., 2004. Computational Ontologies and Information Systems: II. Formal Specification. Communications of the Association for Information Systems, 14, 184-205.

Soares, A. L., Azevedo, A. L. and De Sousa, J. P., 2000. Distributed planning and control systems for the virtual enterprise: organizational requirements and development life-cycle. Journal of Intelligent Manufacturing, 11 (3), 253-270.

Srivastava, R. K., Shervani T. A. and Fahey, L., 1999. Marketing, business processes, and shareholder value: an organizationally embedded view of marketing activities and the discipline of marketing. Journal of Marketing, 63 (Special Issue), 168-179.

Stanford Medical Informatics, What is Protégé-Frames? Available from: http://protege.stanford.edu/overview/protege-frames.html [Accessed February 2011].

Supply Chain Council, 2005. Supply Chain Operations Reference (SCOR) Model, Version 7.0, (www.supply-chain.org).

Swartout, B., Ramesh, P., Knight, K. and Russ, T., 1997. Toward distributed use of large-scale ontologies. Symposium on Ontological Engineering of AAAI, 138-148.

Terzi, S. and Cavalieri, S., 2004. Simulation in the supply chain context: a survey. Computers in Industry, $53(1), 3-16$. 
Tranfield, D., Denyer D. and Smart, P., 2003. Towards a Methodology for Developing EvidenceInformed Management Knowledge by Means of Systematic Review. British Journal of Management, 14 (3), 207-222.

Umeda, S. and Zhang, F., 2006. Supply chain simulation: generic models and application examples. Production Planning \& Control, 17 (2), 155-166.

Uschold, M. and Gruninger, M., 1996. Ontologies: principles, methods and applications. The Knowledge Engineering Review, 11 (2), 93-155.

Uschold, M. and King, M., 1995. Towards methodology for building ontologies. In the Proceedings of the IJCAI-95, Workshop on Basic Ontological Issues in Knowledge Sharing, Montreal, Canada.

Uschold, M., King, M., Moralee, S. and Zorgios, Y., 1998. The enterprise ontology. The Knowledge Engineering Review, 13 (1), 31-89.

van der Zee, D. J. and van der Vorst J. G. A. J., 2005. A modelling framework for supply chain simulation: opportunities for improved decision making. Decision Sciences, 36 (1), 65-95.

Wand, Y. and Weber, R., 1990. An ontological model of an information system. IEEE Transactions on Software Engineering, 16 (11), 1282-1292.

Wand, Y. and Weber, R., 1995. On the deep structure of information systems. Info Systems Journal, 5, 203-223.

Wand, Y., Storey, V. C. and Weber, R., 1999. An ontological analysis of the relationship construct in conceptual modeling. ACM Transactions on Database Systems, 24 (4), 494-528.

Ye, Y., Yang, D., Jiang, Z. and Tong, L., 2008. An ontology-based architecture for implementing semantic integration of supply chain management. International Journal of Computer Integrated Manufacturing, 21 (1), 1-18.

Yin, R. K., 2003. Case Study Research - Design and Methods, Third Edition, Thousand Oaks, California, USA: Sage Publications. 


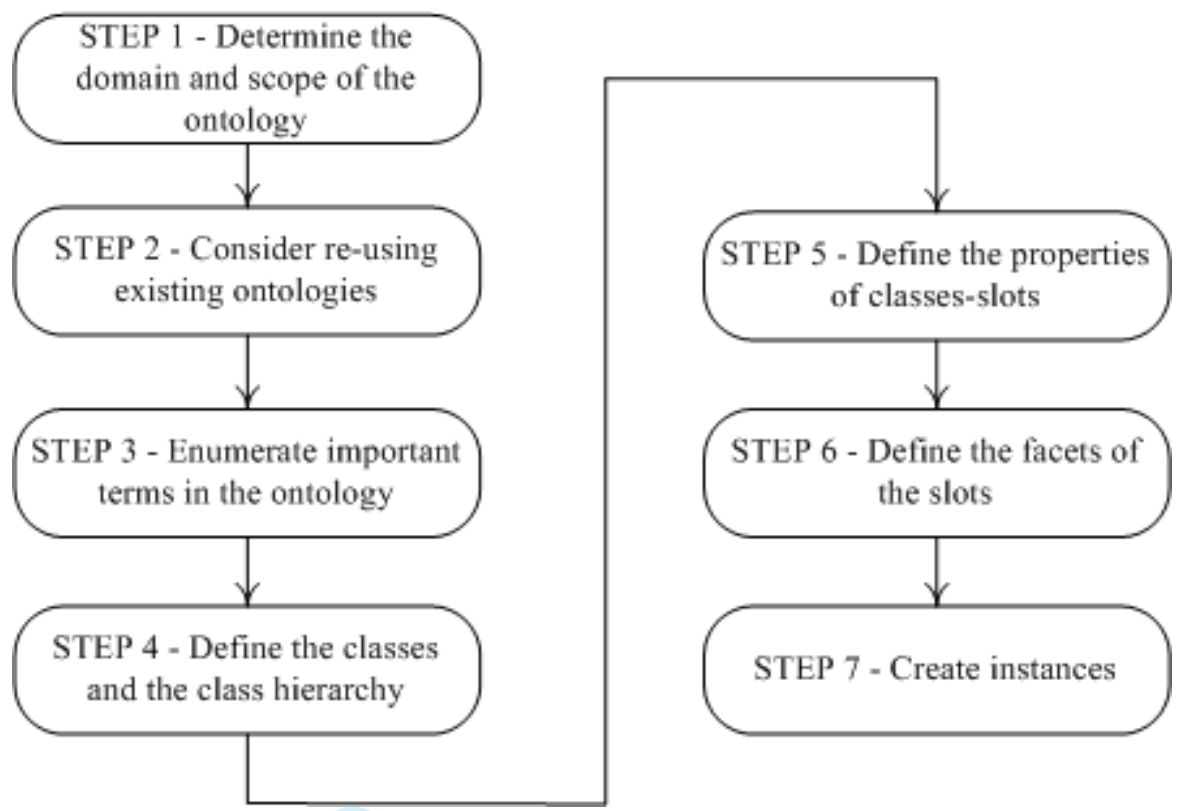

Figure 1: Ontology development approach (Based on Noy and McGuinness 2002) 


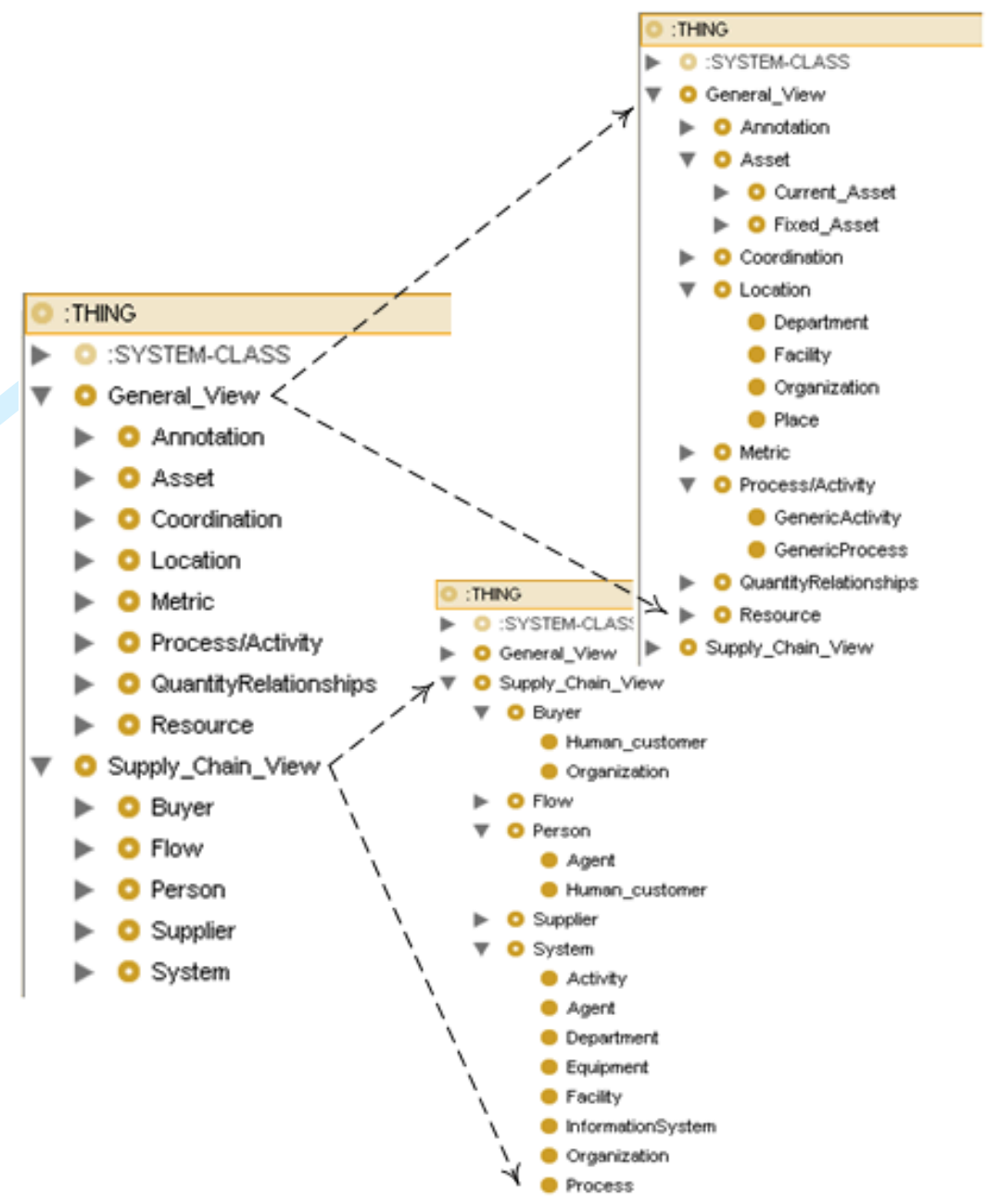

Figure 2: Classes of the ontology model 


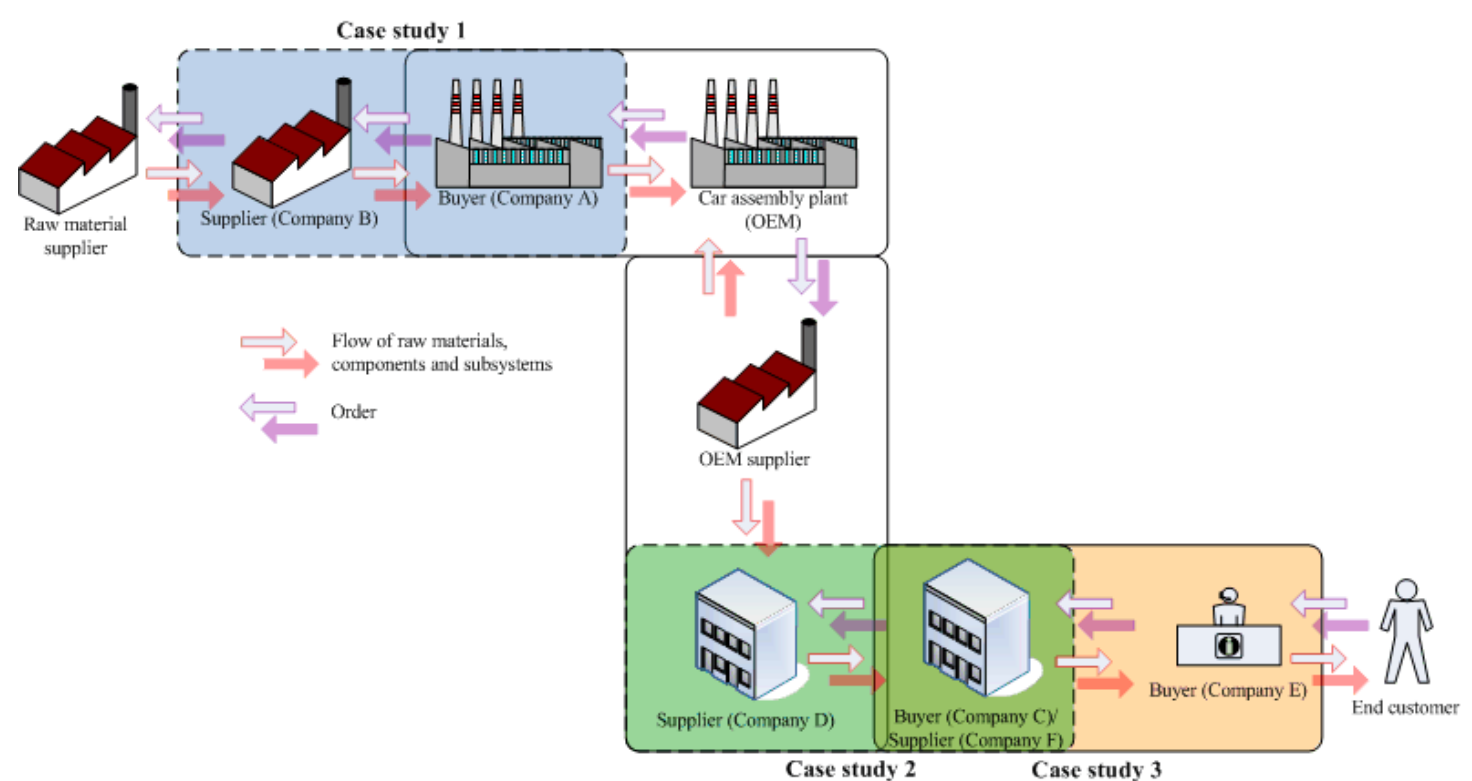

Figure 3: Positions of case study companies relative to the overall supply chain

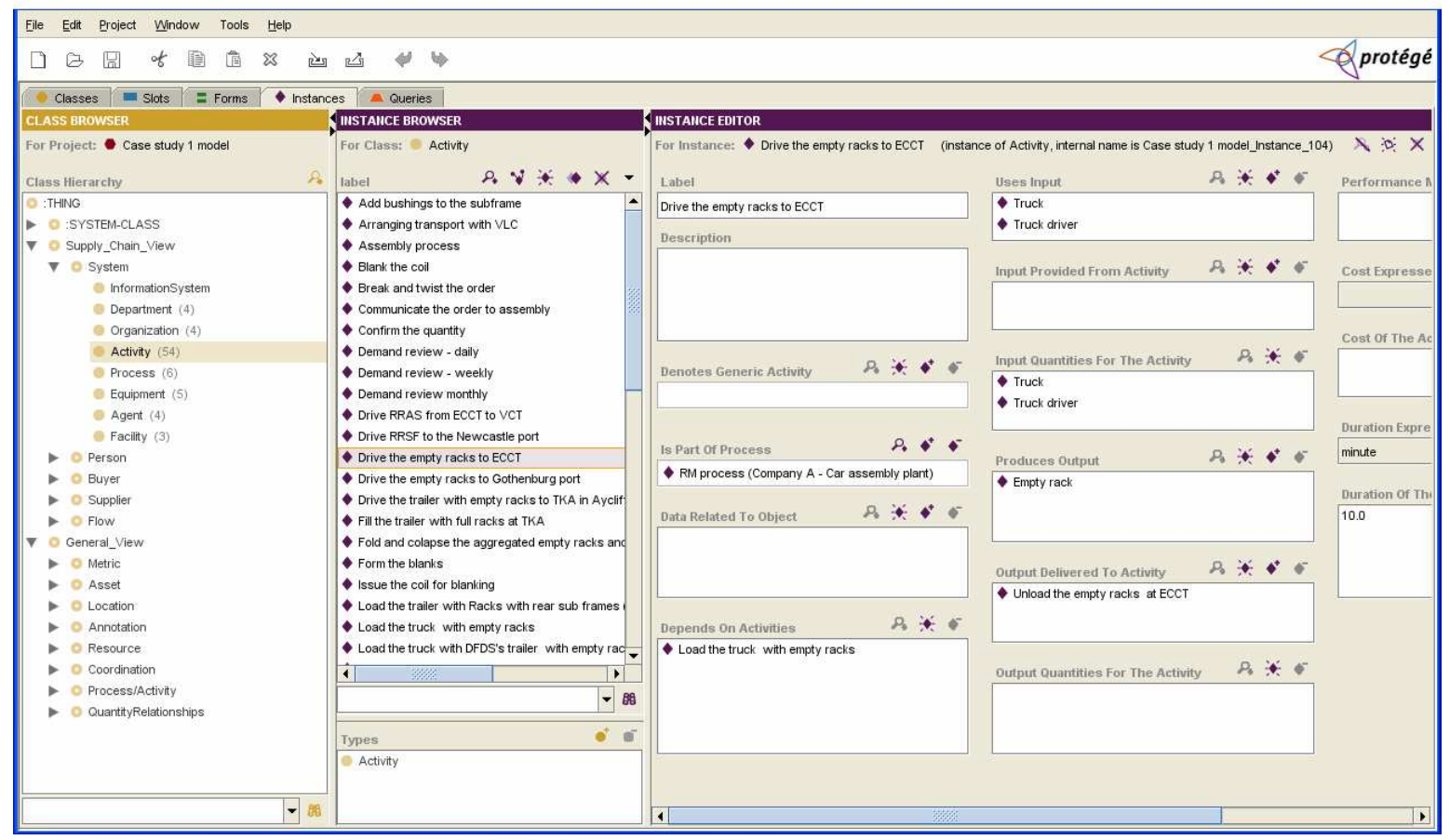

Figure 4: Case study 1 ontology model 


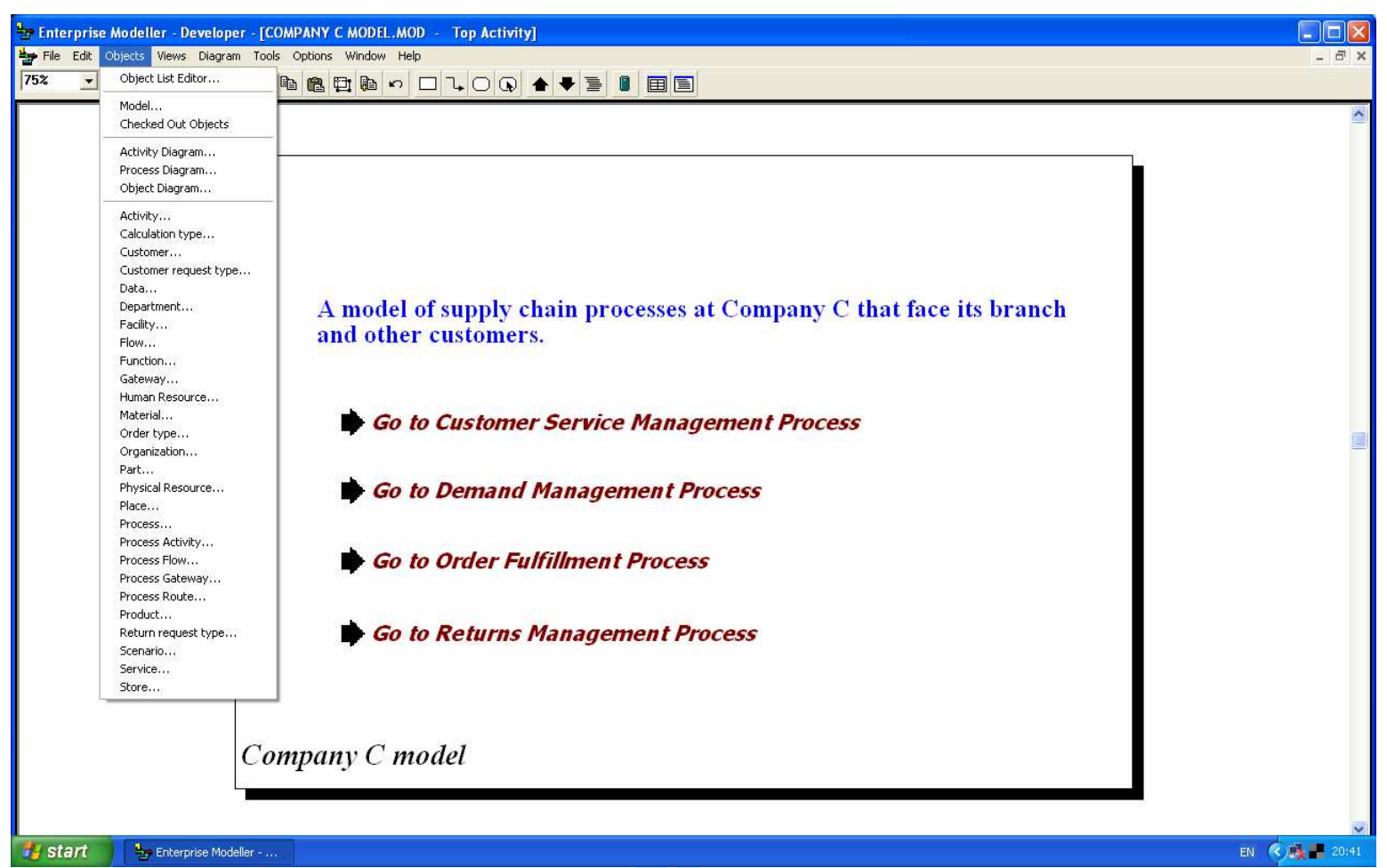

Figure 5: Supply chain process component library 


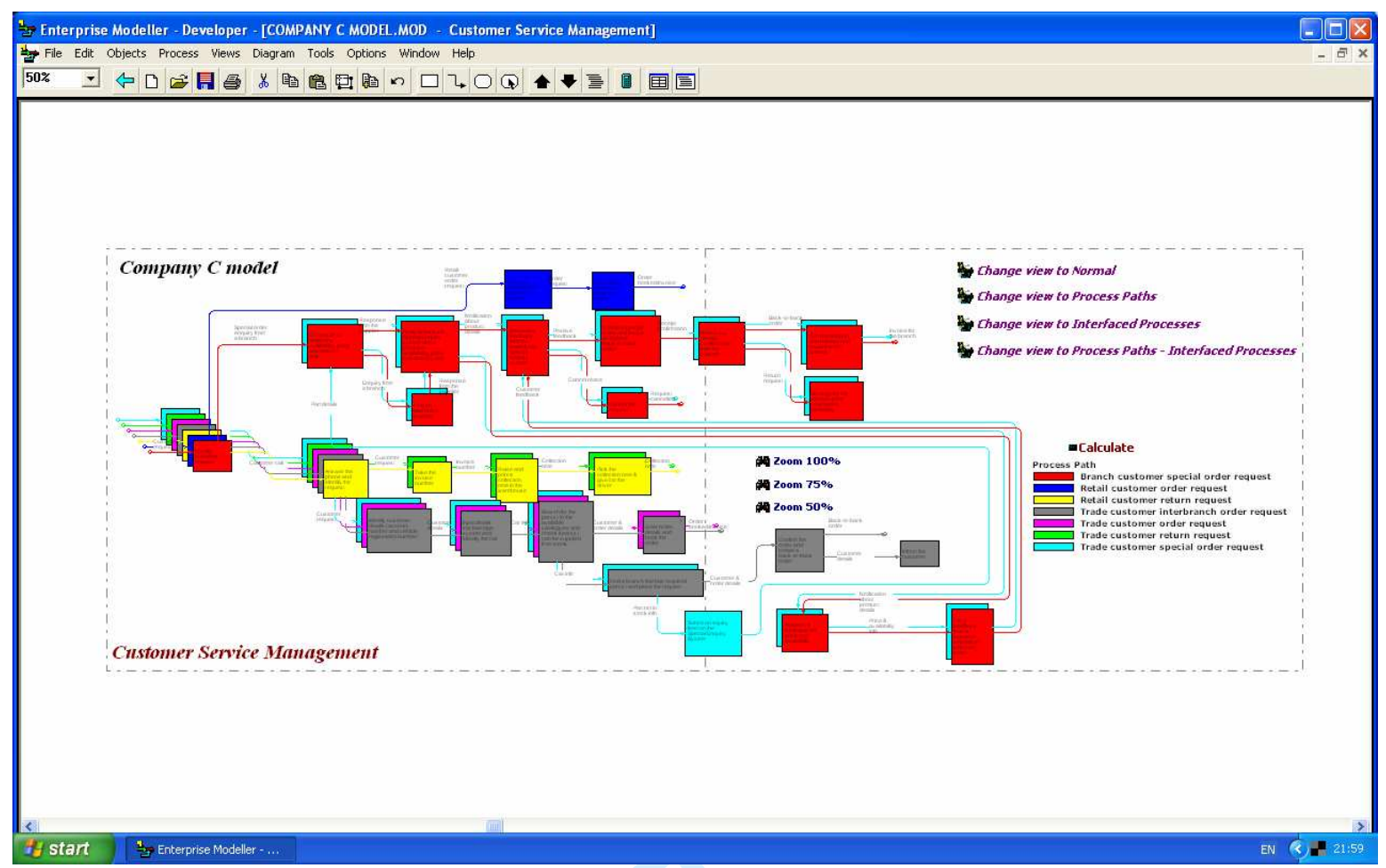

Figure 6: CSM process of Company C 


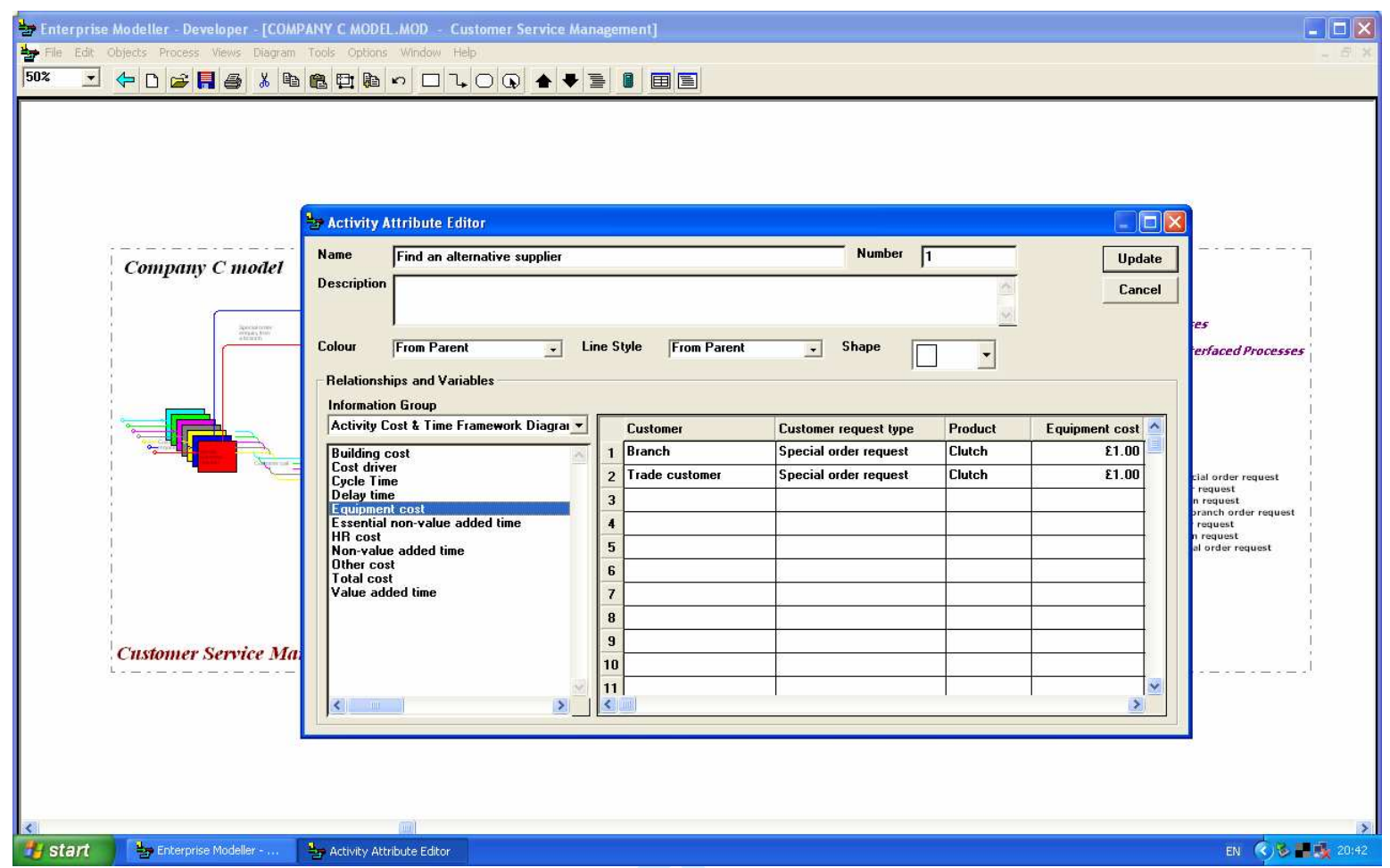

Figure 7: Activity of the CSM process of Company C 
Table 1

Evaluation framework (Adopted from Grubic et al. 2010)

\begin{tabular}{|c|c|c|}
\hline $\mathrm{C \#}$ & Process related criteria & Description \\
\hline 1 & $\begin{array}{l}\text { Business process definition adopted in a supply } \\
\text { chain process framework (SCPF) }\end{array}$ & $\begin{array}{l}\text { Aims to capture different views implied by the } \\
\text { adopted process definition of a SCPF. }\end{array}$ \\
\hline 2 & $\begin{array}{l}\text { Further specification and specialization of a } \\
\text { SCPF's processes }\end{array}$ & $\begin{array}{l}\text { Aims to assess the SCPF's ability to further } \\
\text { specialise and generalise its processes. }\end{array}$ \\
\hline 3 & $\begin{array}{l}\text { Supply chain process levels and decision variables } \\
\text { addressed in a SCPF }\end{array}$ & $\begin{array}{l}\text { Aims to assess the extent to which a SCPF } \\
\text { addresses different decisions variables. }\end{array}$ \\
\hline 4 & $\begin{array}{l}\text { Intra- and inter-company process coordination } \\
\text { capability of a SCPF }\end{array}$ & $\begin{array}{l}\text { Aims to assess the ability of a SCPF to support } \\
\text { intra- and inter-process coordination. }\end{array}$ \\
\hline \multirow[t]{2}{*}{5} & Information sharing ability of a SCPF & $\begin{array}{l}\text { Aims to assess the extent and types of } \\
\text { information shared by a SCPF. }\end{array}$ \\
\hline & Scope related criteria & \\
\hline 6 & Vertical and horizontal scope of a SCPF & $\begin{array}{l}\text { Aims to assess an ability of a SCPF to address } \\
\text { different functional departments that support the } \\
\text { flow of materials and information (horizontal } \\
\text { scope) and how the involved departments } \\
\text { provide input into company's SCM strategy } \\
\text { (vertical scope). }\end{array}$ \\
\hline \multirow[t]{2}{*}{7} & $\begin{array}{l}\text { A SCPF's ability to represent the role of a third } \\
\text { party }\end{array}$ & $\begin{array}{l}\text { Aims to assess an ability of a SCPF to represent } \\
\text { the role of a third party, for example third party } \\
\text { logistics provider. }\end{array}$ \\
\hline & Modelling related criteria & \\
\hline 8 & $\begin{array}{l}\text { A SCPF's ability to describe processes from } \\
\text { different views }\end{array}$ & $\begin{array}{l}\text { Aims to assess an ability of a SCPF to capture } \\
\text { different perspectives (for example, resource, } \\
\text { control, input, etc.) relevant for process analysis } \\
\text { and modelling. }\end{array}$ \\
\hline 9 & A SCPF's ability to allocate cost of activities & $\begin{array}{l}\text { Aims to assess an ability of a SCPF to capture } \\
\text { and allocate costs of different process activities. }\end{array}$ \\
\hline
\end{tabular}

Table 2

Evaluation results (Adopted from Grubic et al. 2010)

\begin{tabular}{l|l|l}
\hline C\# & SCOR model & GSCF framework \\
\hline 1 & Does not address the criteria & Does not address the criteria \\
2 & Addresses the criteria & Addresses the criteria \\
3 & Moderately addresses the criteria & Addresses the criteria \\
4 & Moderately addresses the criteria & Addresses the criteria \\
5 & Does not address the criteria & Does not address the criteria \\
6 & Moderately addresses the criteria & Addresses the criteria \\
7 & Does not address the criteria & Does not address the criteria \\
8 & Does not address the criteria & Addresses the criteria \\
9 & Does not address the criteria & Does not address the criteria \\
\hline
\end{tabular}


Table 3

Eight supply chain processes of the GSCF framework (Adopted from Croxton et al. 2001)

\begin{tabular}{|c|c|}
\hline Supply chain process & Brief description \\
\hline $\begin{array}{l}\text { Customer Relationship } \\
\text { Management (CRM) }\end{array}$ & $\begin{array}{l}\text { The CRM process aims to provide a structure for managing and } \\
\text { developing relationships with customers by identifying and agreeing } \\
\text { product and service agreements (PSAs). }\end{array}$ \\
\hline Supplier Relationship & The SRM process defines how company interacts with its suppliers and it \\
\hline Management (SRM) & is a mirror image of the CRM process. \\
\hline Product Development and & The purpose of the PDC process is to provide a structure for developing \\
\hline Commercialization (PDC) & and bringing to market new products jointly with suppliers and customers. \\
\hline $\begin{array}{l}\text { Customer Service Management } \\
\text { (CSM) }\end{array}$ & $\begin{array}{l}\text { The purpose of the CSM process is to identify and implement necessary } \\
\text { infrastructure required to deliver agreed PSAs to a customer account. }\end{array}$ \\
\hline Demand Management (DM) & $\begin{array}{l}\text { The DM process is concerned with balancing the customer's requirements } \\
\text { with supply chain capabilities. }\end{array}$ \\
\hline Order Fulfilment (OF) & $\begin{array}{l}\text { The OF process includes generating, filling, delivering and servicing } \\
\text { customer orders. }\end{array}$ \\
\hline Manufacturing Flow & The MFM process is associated with coordinating all the manufacturing \\
\hline Management (MFM) & $\begin{array}{l}\text { activities necessary to move products through plants as well as managing } \\
\text { the manufacturing flexibility. }\end{array}$ \\
\hline Returns management (RM) & $\begin{array}{l}\text { The RM process deals with returns, reverse logistics, gatekeeping and } \\
\text { avoidance. }\end{array}$ \\
\hline
\end{tabular}

Table 4

Supply chain ontology models - gaps (Adopted from Grubic and Fan 2010)

\begin{tabular}{|c|c|}
\hline Gap & Brief description \\
\hline 1 & $\begin{array}{l}\text { The level of granularity addressed by supply chain ontology models is mainly on the strategic level and } \\
\text { none of the models addresses tactical and operational levels }\end{array}$ \\
\hline 2 & The methodological approaches adopted are too remote from real supply chain \\
\hline 3 & There is a very limited view on the scope of a supply chain \\
\hline 4 & An explicit account of material traceability and service is missing \\
\hline 5 & A static view on supply chain ontology prevails \\
\hline 6 & $\begin{array}{l}\text { All of the work related to supply chain ontology is centred on the organization and structure of human } \\
\text { knowledge of that reality rather than with the reality itself }\end{array}$ \\
\hline 7 & $\begin{array}{l}\text { There is a restricted view on a supply chain which does not take into the account the whole material } \\
\text { and information flows; only certain aspects of it }\end{array}$ \\
\hline 8 & Taxonomic or class structure view on a supply chain prevails \\
\hline 9 & A perception that ontology reduces to mere terminological problems \\
\hline
\end{tabular}


Table 5

Terms of the SCOR model

\begin{tabular}{l|l}
\hline air, ground...carrier & customer \\
backroom warehouse location & customer order \\
BOM & goods \\
build schedules & order data \\
business rules & product \\
carrier & regulations \\
company's order processing & schedule \\
system & transportation modes \\
configuration rules & vehicles \\
consolidated products & warehouse data \\
contract &
\end{tabular}

Table 6

Terms of the GSCF framework

\begin{tabular}{l|l} 
account or segment manager & inventory \\
channel of distribution & functional silos \\
demand variability & operations \\
functional areas & procurement \\
goal & production \\
performance reports & suppliers \\
products & sales and operations planning \\
profitability of individual & software package \\
customers & transportation planning \\
salesperson & wireless radio frequency technology \\
service levels &
\end{tabular}

Table 7

Preliminary set of classes

\begin{tabular}{l|l}
\hline Asset & Order \\
Customer & Location \\
Facility & Process \\
Information & Function \\
Metric & Interface \\
Plan & Request \\
Practice & Resource \\
Product & Requirement \\
Program & Policy \\
Rule & Guideline \\
Service & Entity \\
Strategy & Document \\
System & Procedure \\
\hline
\end{tabular}


Table 8

Relationships between classes

\begin{tabular}{l|l}
\hline Class & Relationship \\
\hline Interface & Function, Process, Entity \\
Process & Plan, Location, Policy, Strategy, Interface, Entity, Function \\
Function & Entity, Interface, Process \\
Customer & Information, Product, Service \\
\hline
\end{tabular}

Table 9

Five elements of case study design

\begin{tabular}{l|l}
\hline Element & Definition \\
\hline What are case study & $\begin{array}{l}\text { How are material and information flow supported supply chain processes } \\
\text { structured in industrial organisations? }\end{array}$ \\
\hline \multirow{4}{*}{$\begin{array}{l}\text { What are case study } \\
\text { propositions? }\end{array}$} & $\begin{array}{l}\text { Due to complexity of supply chains, several supply chain processes } \\
\text { exist, each addressing specific aspect of material and information flows. }\end{array}$ \\
\cline { 2 - 2 } & $\begin{array}{l}\text { These processes affect a company's immediate suppliers and/or } \\
\text { customers. }\end{array}$ \\
\cline { 2 - 2 } $\begin{array}{l}\text { What is the unit of } \\
\text { analysis? }\end{array}$ & $\begin{array}{l}\text { Material and information flows between a company and its supplier or } \\
\text { customer. }\end{array}$ \\
\hline \multirow{2}{*}{$\begin{array}{l}\text { What is the logic that } \\
\text { links the data to the } \\
\text { propositions? }\end{array}$} & $\begin{array}{l}\text { Data gathered in case studies should be collected on these flows and } \\
\text { converge in triangulating fashion by means of: semi-structured } \\
\text { interviews, walking the processes (observation) and secondary data } \\
\text { (organisational charts, process maps, etc.). }\end{array}$ \\
\hline $\begin{array}{l}\text { What are criteria for } \\
\text { interpreting the } \\
\text { findings? }\end{array}$ & $\begin{array}{l}\text { Once collected, the data will then be used to develop supply chain } \\
\text { process maps which, after being validated by case study companies, } \\
\text { should provide input to validate/enrich the ontology model. }\end{array}$ \\
\hline
\end{tabular}

Table 11

Multidimensionality in supply chain processes - example from Company C

\begin{tabular}{l|l}
\hline Supply chain process & Dimension \\
\hline CSM process & Customer type, customer request type, product \\
DM process & Calculation type, branch \\
RM process & Customer type, return request type, product \\
OF process & Customer type, order type, product, goods-in type \\
\hline
\end{tabular}


Table 10

Case studies and case study companies - an overview

\begin{tabular}{|c|c|c|c|c|c|c|}
\hline & \multicolumn{2}{|c|}{ Case study 1} & \multicolumn{2}{|c|}{ Case study 2} & \multicolumn{2}{|c|}{ Case study 3} \\
\hline & Company A & Company B & Company C & Company D & Company E & Company F \\
\hline Sector & $\begin{array}{l}\text { Automotive } \\
\text { manufacturing }\end{array}$ & $\begin{array}{l}\text { Automotive } \\
\text { manufacturing }\end{array}$ & $\begin{array}{l}\text { Automotive } \\
\text { aftermarket }\end{array}$ & $\begin{array}{l}\text { Automotive } \\
\text { aftermarket }\end{array}$ & $\begin{array}{l}\text { Automotive } \\
\text { aftermarket }\end{array}$ & $\begin{array}{l}\text { Automotive } \\
\text { aftermarket }\end{array}$ \\
\hline No. of employees & $100-200$ & $500-1,000$ & $1,000-1,500$ & $50-100$ & $10-20$ & $1,000-1,500$ \\
\hline Role in a dyad & Buyer & Supplier & Buyer & Supplier & Buyer & Supplier \\
\hline $\begin{array}{l}\text { Immediate } \\
\text { customers }\end{array}$ & Car assembly plant & OEMs worldwide & $\begin{array}{l}\text { Retail customers, } \\
\text { garages and } \\
\text { branches }\end{array}$ & $\begin{array}{l}\text { Major UK car and } \\
\text { commercial } \\
\text { vehicles part } \\
\text { dealers } \\
\end{array}$ & Garages & $\begin{array}{l}\text { Retail customers, } \\
\text { garages and } \\
\text { branches }\end{array}$ \\
\hline $\begin{array}{l}\text { Materials } \\
\text { observed }\end{array}$ & $\begin{array}{l}\text { Major structural } \\
\text { subsystem (comes } \\
\text { in two variants) for } \\
\text { a high-end car } \\
\text { model (comes in } \\
\text { numerous different } \\
\text { variants) } \\
\end{array}$ & $\begin{array}{l}\text { Components (come } \\
\text { in two variants) for } \\
\text { the major structural } \\
\text { subsystem }\end{array}$ & $\begin{array}{l}\text { The same line of } \\
\text { parts as supplied by } \\
\text { Company D }\end{array}$ & $\begin{array}{l}\begin{array}{l}\text { Line of parts } \\
\text { (almost } 2,000)\end{array} \\
\text { which accounts } \\
10 \% \text { of total SKUs } \\
\text { of this company }\end{array}$ & $\begin{array}{l}\text { The same line of } \\
\text { parts as supplied by } \\
\text { Company D }\end{array}$ & $\begin{array}{l}\text { The same line of } \\
\text { parts as supplied by } \\
\text { Company D }\end{array}$ \\
\hline $\begin{array}{l}\text { Identified supply } \\
\text { chain processes }\end{array}$ & OF and RM & $\begin{array}{l}\text { DM, MFM and OF } \\
\text { (RM) }\end{array}$ & $\begin{array}{l}\text { DM, CSM, OF and } \\
\text { RM }\end{array}$ & CSM, OF and RM & CSM, OF and RM & $\begin{array}{l}\text { DM, CSM, OF and } \\
\text { RM }\end{array}$ \\
\hline
\end{tabular}


Dear Editor in Chief of International Journal of Computer Integrated Manufacturing,

Our paper has now been revised in line with the reviewers' comments. This document explains the changes made and gives our responses to reviewers' for those areas where we felt only additional clarification was needed. All the changes made and referred to below have been in the manuscript marked in red colour. Also, further references have been added to address your comment number 3. In total, the revised version is 8,892 words long (including references), meaning it is almost 1,100 words longer than the originally submitted version $(7,817)$.

Our explanations are divided in two parts, thus reflecting the comments made by reviewers separately.

\section{$\underline{\text { Revisions and responses: }}$}

\section{Changes to address the comments of Reviewer 1:}

This reviewer is generally very positive about the paper and feels it could be published subject to some minor amendments and clarifications. These are grouped as follows:

1. "Make the differences between the proposed approach and others review in the literature explicit, possibly through a table." that is "It is not clear how the proposed ontology differentiates from other such approaches discussed in the paper such as SCOR. Perhaps a table comparing features and characteristics of each approach with the one that is proposed in the paper would be useful way of doing this."

Our response: The ontology model introduced is proposed to provide support, in the form of necessary building blocks, and facilitate supply chain modelling and analysis. From this perspective, the model and other approaches mentioned in the paper, like SCOR or GSCF, serve different purposes. Hence, they have little common grounds to be compared. For example, the latter two were developed to support and promote process view on supply chains. And although they support some limited analysis this capability is still not at the same level as it is made possible by our ontology model. And the reason for this is because they were built to serve different purposes. 
Nevertheless, these two frameworks, especially the GSCF, played an important role in the development of ontology model. Approaches this ontology model could be compared with are supply chain ontology models developed to serve similar purpose and these were already introduced and to some extent reviewed in the paper (section 3.2.2). From that perspective, our model advances the field of supply chain ontology by explicitly addressing two gaps found in these models. Nevertheless, this point is further clarified and stressed on p. 10.

2. "Make the methodological basis explicit." More specifically "how did the authors arrive at these conclusions? What was done in the case studies? what was recorder, said, observed, etc? and what was the analysis that lead to the insights and conclusions outlined in the paper?"

Our response: An attempt was made in section four to better explain the rationale behind case study execution, data collection, and analysis and synthesis (pages 15, 16 and 17. Then, in 4.3.1 and 4.3.3, by giving couple of examples from our case studies, we tried to explain what has led us to those conclusions. Apart from this, we would also like to reiterate a point already made in the original manuscript about the complexity of ontology validation in general but especially when this kind of empirical research is used for this purpose. This has not only made this work a true pioneering attempt in this direction but it made it harder due to the lack of insights which we could build on.

3. "Outline the future research challenges/priorities as well as outlining your own intentions as to what you are proposing to do next." Since this is very similar to the comment made by Reviewer 2 (under question 6 and in the 'Conclusions' section of the Comments to Author), we decided to group them and explain our response to both reviewers here.

Our response: To highlight the main achievements and give our view on future research activities in the area of ontology application and validation, we have entirely rewritten section 6 . Three propositions for future research are made there.

\section{Changes to address the comments of Reviewer 2:}

This reviewer finds the idea of integrating supply chain ontology with processes interesting but suggests changes in the following three areas: (1) further references in 
the area of supply chain modelling, (2) explanations regarding the ontology development tool and language used as well as providing more details about ontology structure, and (3) case studies to validate the ontology model.

\section{Further references in the area of supply chain modelling}

Our response: Although reviewer 1 holds that the paper "includes a significant and relevant literature review" we have closely considered the comment and the four papers suggested by the second reviewer and this is our answer. The papers suggested offer a valuable contribution to supply chain modelling research and practice but they do not directly contribute to our study. Namely, these papers, together with many other papers addressing this topic by proposing different methods and techniques for this (e.g. various types of simulation techniques, heuristics, mathematical modelling, optimisation techniques, etc.) serve different purpose than the one proposed by our model. The purpose of our literature review presented in section 1 was not to provide an elaborate overview of all methods and techniques in use today (a whole paper would be necessary for this) but only to point to a lack of consideration for a supply chain process component. Neglecting this aspect, as is the case with the studies suggested by this reviewer, does not affect the results and applicability of their findings. Meaning, we are talking about different levels of analysis granularity. But if we want to more closely analyse and manage time and costs in supply chain processes and act upon this analysis, then neglecting this aspect would be erroneous. In that case we need to define and articulate the key supply chain processes. And this is what our ontology model is really developed to support. Therefore, in our literature review we studied only supply chain modelling approaches which promise to provide a comprehensive account of a supply chain and found they all lack a supply chain process component. By identifying the key supply chain processes, and then building upon them, our ontology model is an attempt to complement them with specifically developed building blocks which further enrich their description, modelling, analysis, and applicability. But this does not mean that we have included all the relevant studies of this kind. Although we tried to identify and include all the relevant studies we also may have accidently missed some important ones. Hence, if you know of any relevant papers that we have missed, we are more than happy to analyse and subsequently include them in our reference list. 
2. Ontology development tool, languages, and presentation

Our response: The version of Protégé used to develop our ontology model is 3.2 and we have made a change in the manuscript to highlight this (p. 8). We used Protégé's frames editor tool and not OWL or any other language directly. This is because we wanted to use this tool to define our classes and their properties in a way so they provide necessary elements for modelling and analysing supply chain processes. Hence, our intention was not to achieve exchange or interoperability of data between different systems. Also, there was no need for any reasoning capability. Regarding the ontology's structure and presentation, we have made changes to both section 3.2.4 and Figure 2 to address this issue. Figure 2 was changed completely and new one was produced and included to show more of the ontology classes (see Figuresrevised.doc). Similarly, text was expanded to reflect this change. But mainly due to space limitations we could not add more text here without further increasing the manuscript's size. Hence, in our text we stated that more information about classes and their properties will be provided by the authors upon request. If deemed important and necessary, we can also include this information as an appendix.

3. Case studies to validate the ontology model

Our response: In addressing this comment, we expanded section 5 (p. 21 and 22) to show the extent of industrial application to which the proposed ontology has so far been subjected to.

Kind regards,

Authors 